\title{
Cause Analysis and Treatment of Cracks in Bridge Pier under High Filling Soil
}

\author{
Liu Qiang ${ }^{1, ~ a, ~ Y u ~ B o ~}{ }^{2, b}$ and Jiang Xianglin ${ }^{2, c}$ \\ 1Jiangxi GanEWan Road and Bridge Investment Co., Ltd, Jiujiang China \\ ${ }^{2}$ Jiangxi Transportation Institute, Nanchang China

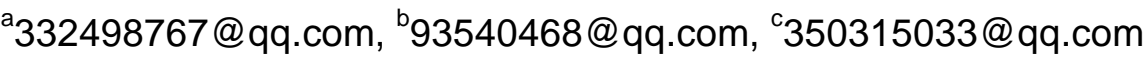

\begin{abstract}
Keywords: Bridge pier; High filling soil; Overloading effect; Cracks
Abstract. A $30 \mathrm{~m}$ fabricated prestressed concrete simply supported T-beam bridge uses a pile foundation as its lower structure. Owing to the filled engineering spoil at the abutment side, which is higher than the original ground line $11.87 \mathrm{~m}, 8$ cracks formed in the side of 3 pier columns adjacent to abutment within the range of $1 \mathrm{~m}$ above the filling line. According to the shape and location of the cracks, the corresponding calculation model is established by dividing the pier column into two sections of above and below the soil. The causes of the cracks formation and their influence on the structure are analyzed quantitatively. The correctness of the calculation model is verified by disease phenomena detected subsequently. Considering the poor stability of the filling soil, the spatula around the pier was stratified and cleaned, and then the crack was stable and the shear deformation of the support was basically restored.
\end{abstract}

\section{Introduction}

During the construction of bridges in mountainous areas or heavy hilly areas, valley topography is very common. For the sake of economy, the deep trench below the bridge is often used as the spoil ground of the subgrade. The filling soil produces unbalanced pressure on one side of the pier, which may cause large lateral deformation, deflection and even cracks of the pier, and the pier could be pushed down in some serious cases. Generally, compared to the vertical settlement displacement, the lateral displacement of soil caused its instability is more important, especially for the concrete piers. It is necessary to study the mechanisms of bridge pier damage under the action of soil fill and its influence on the safety performance of the whole bridge, for the ability of the bridge to withstand horizontal load is not considered in the initial design.

\section{Engineering Overview}

The superstructure of a bridge uses a $30 \mathrm{~m}$ fabricated prestressed concrete simply supported $\mathrm{T}$ beam, contains $7 \mathrm{~T}$-beam in the horizontal with the neighboring beam spacing for $2 \mathrm{~m}$. The abutment of the lower structure are numbered $0 \sim 10$, of which 0 \# is the column abutment, the 10 \# abutment is the ribbed abutment, the \# 1 9 \# is the column pier with pile foundation (the bridge pier is made by C30 concrete and pile foundation is made by $\mathrm{C} 25$ concrete). The original ground line flushes with the top of the beam under the pillars, and the elevation is $68.632 \mathrm{~m}$. The actuality is that the bridge lies in the col, due to the filling of engineering spoil, the elevation of real fill line is $80.500 \mathrm{~m}$, higher than the original ground line $11.87 \mathrm{~m}$. From the field detection, 8 cracks $(1 \sim 8 \#$ cracks $)$ are found in the side of 3 pier columns of the 9 \# pier within the range of $1 \mathrm{~m}$ above the filling line, which is close to $8 \#$ pier. The fractures of the cracks were shown in Figure 1 and their details were listed in Table 1. 


\section{Analysis of Cracks in Bridge Pier}

A. Mechanisms for High Filling Soil acting on Piers

Table 1 Parameters of the cracks

\begin{tabular}{c|cccc}
\hline Pier column Number & Crack number & Length [m] & Width [mm] & Position \\
\hline \multirow{3}{*}{$1 \#$} & 1 & 1.35 & $0.1 \sim 3$ & Above the soil \\
& 2 & 0.9 & $<0.15$ & Above the soil \\
& 9 & 1.0 & $<0.15$ & Inside the soil \\
\hline \multirow{3}{*}{$2 \#$} & 3 & 0.65 & $<0.15$ & Above the soil \\
& 4 & 0.95 & $<0.15$ & Above the soil \\
& 10 & 1.1 & $<0.15$ & Inside the soil \\
& 11 & 1.0 & $<0.15$ & Inside the soil \\
\hline \multirow{5}{*}{$3 \#$} & 5 & 1.1 & $<0.15$ & Above the soil \\
& 6 & 0.9 & $<0.15$ & Above the soil \\
& 7 & 0.7 & $<0.15$ & Above the soil \\
& 8 & 1.2 & $<0.15$ & Above the soil \\
& 12 & 1.3 & $<0.15$ & Inside the soil \\
& 13 & 1.2 & $<0.15$ & Inside the soil \\
\hline
\end{tabular}
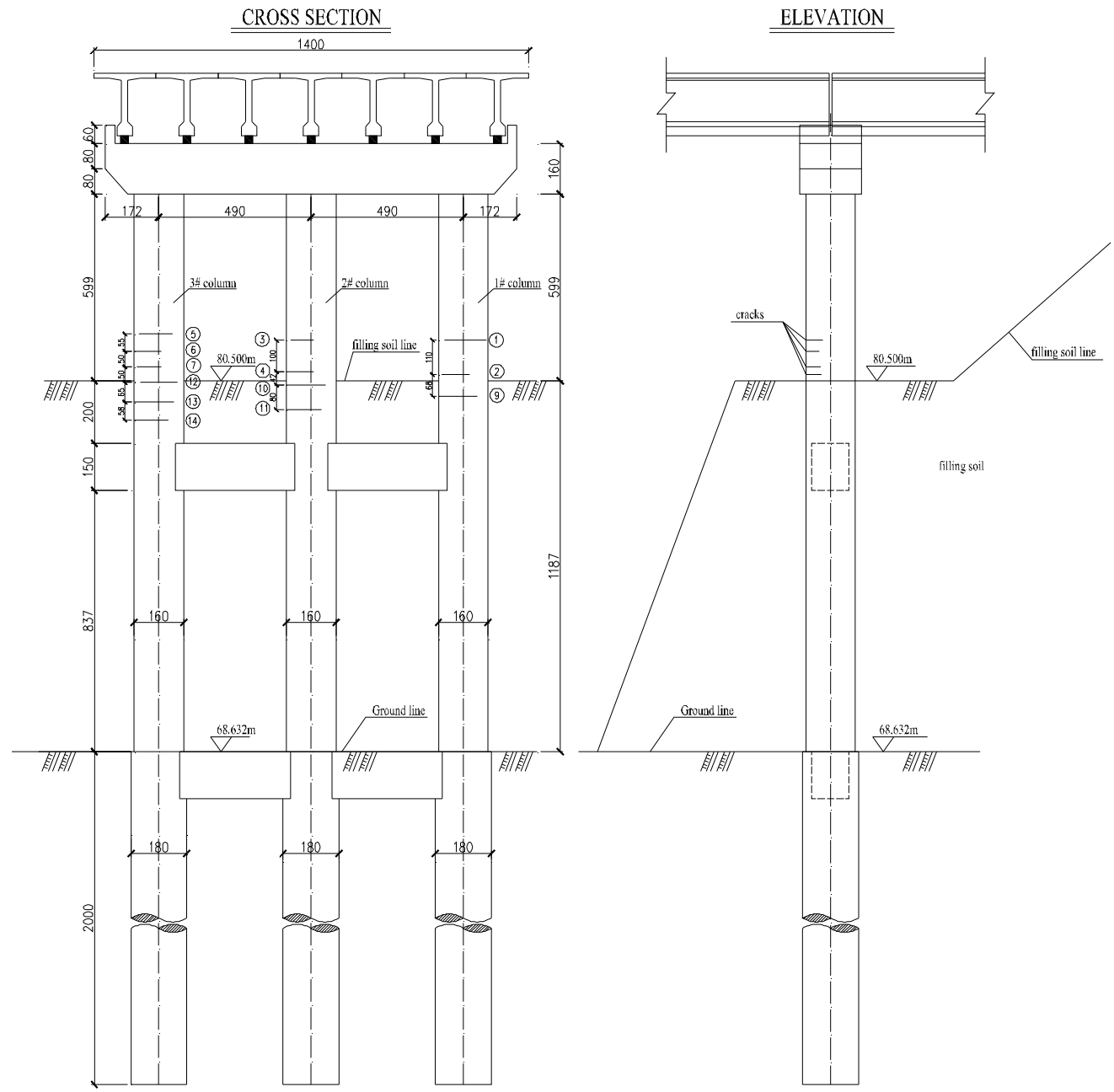

Figure 1 Bridge cross section \& distribution of crack and filling soil [cm]

The high filling soil makes its role by forming a load on the original base soil. This load produces horizontal thrust on the pier above the ground ${ }^{[1][2]}$ besides increasing the vertical load. The effect of filling soil on adjacent piles mainly includes the following two aspects: 
1. The instability of the filling causes the soil to slide downward along the original surface, which then squeezes the pier, resulting in its bending, horizontal movement or shear damage.

2. Filling causes settlement deformation of the soil around the pier, the soil occurs a downward displacement relative to the pile and the following downward negative friction, which increases the axial load of the pier and produces additional settlement, causing uneven settlement of the soil. This is detrimental to the superstructure.

For the filling acting on the piers, the pier is affected by the deformation or movement of the surrounding soil under the action of its deadweight, which belongs to the passive force.

\section{B. Mechanical Calculation Model of Bridge Piers}

The design of the pier always based on its vertical carrying capacity. Under the lateral force of the high filling on the bridge, the pier cracking is inevitable. The working performance of the pier under the action of high filling is very complicated because the pier is semi-rigid and the soil is elastoplastic. Under pressure of the filling, the pier occurs the flexural deformation overcoming by the material strength of itself. With development of the flexural deformation, the soil at one side of the pier is squeezed to produce resistance, which will prevent further development of the flexural deformation of the pier body. So these constitute a complex interaction system between bridge piles and soil ${ }^{[3,4]}$.

To simplify the force analysis of pier, the pier is analyzed in two parts by location, i.e., the soil above and soil inside.

1. Force analysis for the pier column part above the soil

Cracks found in the pier appeared in the range of $1 \mathrm{~m}$ above the soil. In order to analyze force of the pier, a single pier above the soil was divided out independently for analysis, as shown in Figure 2.

The top of the pier is subjected to the $\mathrm{P}_{0}$ effect caused by the self-weight of the superstructure, and the $\mathrm{F}_{0}$ effect derived from the bearing preventing the horizontal deformation of the pier top. The distance of the pier top to the crack is $6.5 \mathrm{~m}$. The weight of the superstructure is $6200 \mathrm{kN}$, divided into three pillars, the average of which, $\mathrm{P}_{0}$, is $2066.7 \mathrm{kN}$; the pier and the cover beam dead-weight $\mathrm{G}$ is $609.1 \mathrm{kN}$. According to the force balance equation,

$$
\left\{\begin{array}{l}
P_{1}=P_{0}+G=2675.8 \mathrm{kN} \\
F_{1}=F_{0} \\
M=F_{0} L
\end{array}\right.
$$

The diameter of the pier is $1.6 \mathrm{~m}$, the area $\mathrm{A}$ is $2.011 \mathrm{~m}^{2}$, and the resistance of the circular cross section outer edge is $0.4021 \mathrm{~m}^{3}$. Once the pier body is cracked, the tensile stress on the surface of the pier, $\sigma$, is at least greater than the tensile strength standard value $\sigma_{t k}=2.01 \mathrm{MPa}$ of C30 concrete.

$$
\begin{aligned}
\sigma & =\frac{M}{W}-\frac{P_{1}}{A} \\
& =\frac{F_{0} L}{W}-\frac{P_{0}+G}{A}>\sigma_{t k}=2.01 \mathrm{MPa} \\
F_{0} & >\frac{\left(\sigma_{t k}+\frac{P_{0}+G}{A}\right) W}{L} \\
& =\frac{\left(2.01 \times 10^{6}+\frac{2675.8 \times 10^{3}}{2.011}\right) \times 0.4021}{6.5}=206.6 \mathrm{kN} \\
M & =F_{0} L>1342.9 \mathrm{kN} \cdot \mathrm{m}
\end{aligned}
$$

It can be seen that, each pillar column shares the horizontal force of at least $206.6 \mathrm{kN}, 3$ pillars do total horizontal force of at least $619.8 \mathrm{kN}$. If the horizontal force is born through the rubber bearing horizontal friction, there are totally 14 GJZ300 $\times 400 \times 74$ type plate rubber bearing at the pier top, then the horizontal stiffness of each bearing is $1622 \mathrm{~N} / \mathrm{mm}$. 
The shear deformation of each bearing, $\delta$, could be obtained as:

$\delta>\frac{619.8 \times 10^{3}}{14 \times 1622}=27 \mathrm{~mm}$

The shear deformation of the bearing was checked in the field, and the measured value for deformation of 14 bearings were between $18 \sim 26 \mathrm{~mm}$. The average value was $23 \mathrm{~mm}$, which was basically equal to the calculated one. The reason for the measured value lower than the calculated one is that the actual horizontal stiffness of the plate rubber bearing is larger. In addition, the dumping of the soil during the filling process and the use of the bulldozer during the loading process produce unfavorable conditions for the pillar columns, and the structural deformation has been partially restored.

2. Force analysis for the pier column part inside soil

The horizontal force P1, the horizontal force F1 and the bending moment $\mathrm{M}$ are used to establish the pile-soil interaction model, as shown in Figure 3. The distribution of the bending moment of the pier along the depth could be obtained, as shown in Figure 4.

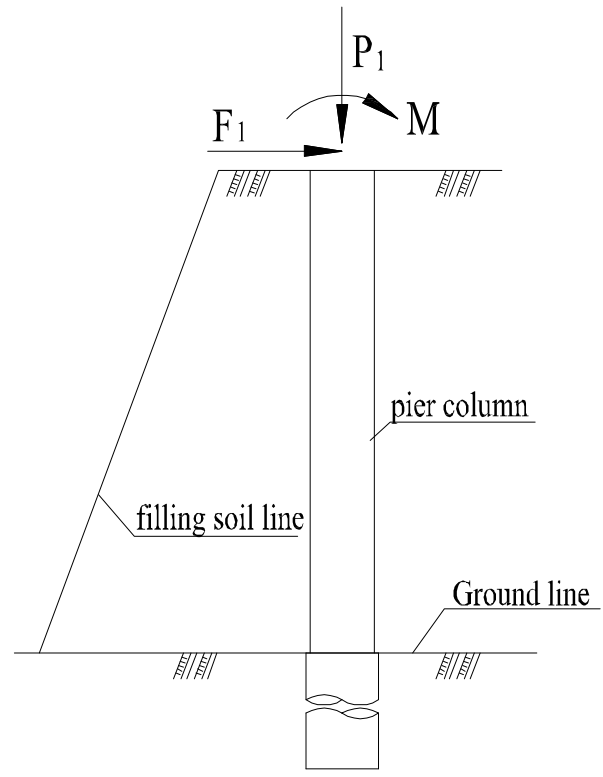

Figure. 3 Force model of pier inside the filling

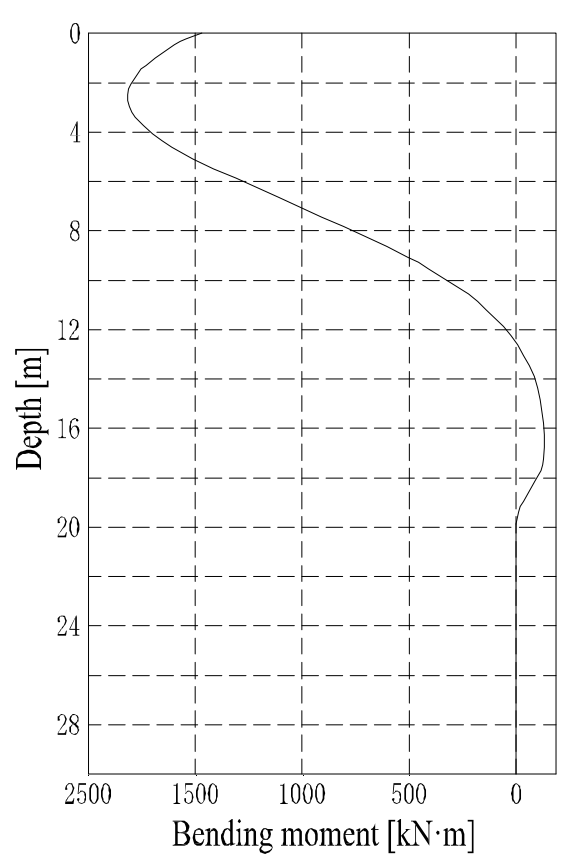

Figure 4 Distribution of bending moments along the depth of embedment

It can be seen from Figure 4 that the bending moment is the largest at $2 \mathrm{~m}$ below the surface of the filling, and the bending moment in the range of $5 \mathrm{~m}$ below the filling surface is larger than that of the cracked areas. After removing the filling, the cracks in the range of $5 \mathrm{~m}$ below the filling surface are checked, and five new cracks are found. The crack width is less than $0.15 \mathrm{~mm}$, one crack for 1 \# pillar column, two for 2 \# and 3 \# pillar columns, respectively, which concentrated in the range of $2 \mathrm{~m}$ below the filling surface. The actual crack distribution range is different from that of the model calculation. There is a certain discrepancy between the actual crack distribution and the model prediction, the main reason is that there is a tie beam (Figure 1) between the pillars at the lactation of $2 \mathrm{~m}$ below the filling surface and its section stiffness is relatively large.

\section{Conclusions}

The calculation model is established by quantitative analysis of the stress state of the pier column, and its accuracy is verified by the phenomenon observed in the field.

Due to its poor stability especially under the action of water, the filling soil has the risk of landslide, which could cause damage to the pier column. For this problem, removing the spill around the pier, and 
using closed repair method for the structural cracks with width below $0.15 \mathrm{~mm}$ and chemical grouting method for ones with width above $0.15 \mathrm{~mm}$. After the spoil clean up, the crack is stable, without further development and the bearing shear deformation is basically restored.

\section{References}

[1] WU Xuhua, YUAN Shulin and DEN Shuang: Bridge Pier Column Offset Analysis and Rectification Treatment. Highway Engineering. Vol. 38, No.1(2013), p. 146-148

[2] SONG Ning, XU Hong-yuan, ZHONG Yuan,YIN Heng and LI Wang-hui: Strengthening Strategies for Bridge Structure Damage Induced by Soil Lateral Movement. Highway. No.7(2012), P. $65-71$

[3]TAO Ying: Study on the Injury Mechanism of Bridge Piers and the Safe Capability of Bridge under High Filling Soil. A Dissertation submitted for the Degreee of Master. Chongqing Jiaotong University(2014).

[4]LI Guo-hao: Analysis of Horizontal Displacements, Internal Forces and Load-carrying Capacity of Piles. Shanghai Lixue. No. 1(1981), p. 1-10 